Running head: STUDYING AND SOCIAL NORMS

Self-Regulated Studying Behavior, and the Social Norms that Influence It J. R. Eyink*a, B. A. Motz*a , G. Heltzel ${ }^{\mathrm{a}}$, \& T. M. Liddell ${ }^{\mathrm{a}}$

Author Affiliations:

${ }^{a}$ Department of Psychological and Brain Sciences

Indiana University

1101 E. $10^{\text {th }}$ Street

Bloomington, IN 47405

Author Note:

* Denotes co-first authors. This research was supported by a grant from the APS Fund for Teaching and Public Understanding of Psychological Science. The authors thank Ed Hirt for assistance designing the email interventions, and Matt Mallon for software development that supported data collection for this research.

Corresponding Author:

bmotz@indiana.edu 
Running head: STUDYING AND SOCIAL NORMS

\begin{abstract}
Teachers use injunctive norms when telling students what they should be doing. But researchers find that sometimes descriptive norms, information about what others are doing, more powerfully influence behavior. Currently, we examine which norm is more effective at increasing self-regulated studying and performance in an online college course. We found injunctive norms increased study behaviors aimed at fulfilling course requirements (completion of assigned activities), but did not improve learning outcomes. Descriptive norms increased behaviors aimed at improving knowledge (ungraded practice with activities after they were due), and improved performance. These results imply norms have a stronger influence over behavior when there is a match between the goal of the behavior (fulfilling course requirements vs. learning goals) and the pull of a stated norm (social approval vs. efficacy). Because the goal of education is learning, this suggests descriptive norms have a greater value for motivating selfregulated study in authentic learning environments.
\end{abstract}


Running head: STUDYING AND SOCIAL NORMS

Self-Regulated Studying Behavior, and the Social Norms that Influence It

To help students succeed, teachers often need to motivate students to change their behaviors: to work through practice problems, to space their studying, or to interleave different types of study materials, among others (Dunlosky et al., 2013). These studying behaviors typically occur outside the classroom, limiting the amount of oversight that a teacher can exert. Moreover, many of the benefits of self-regulated study require the learner's active effort and monitoring (Bjork et al., 2013; Fernandez \& Jamet, 2016), possibly with diminishing returns when a studying regimen is explicitly enforced (e.g., Ciccone \& Brelsford, 1976; Carvalho et al., 2016). Therefore, a significant challenge instructors face is how to improve studying effort, when that effort is under the student's control.

A common practice aimed at improving effort is to give students information on what they should be doing. In college, for example, syllabi might tell students they should engage in specific studying strategies (Parkes \& Harris, 2002), course announcements might inform students when they should begin studying in preparation for an exam (McCabe \& Meuter, 2011), or direct instruction might be used to teach students the benefits of a study technique that they should be using (Ariel \& Karpicke, 2017).

To us, it seems clear that these actions (unintentionally or intentionally) create social norms by producing "rules and standards that are understood by members of the group [i.e. those enrolled in the course] and that guide...behavior without the force of laws” (Cialdini \& Trost, 1998). What is less clear, however, is whether a teacher's statement of what students "should” do is an effective motivator toward these desirable behaviors. The goal of the current study is to evaluate the strength of different social norm interventions for motivating self-regulated studying behavior in a college course. 
Running head: STUDYING AND SOCIAL NORMS

\section{Social Norms}

Since Asch (1956) and Sherif (1936), decades of research demonstrates that people conform to the expectations and behaviors of others, either to gain social approval or behave correctly in a situation. These correspond to different types of normative information: injunctive and descriptive norms, respectively (Deutsch \& Gerard, 1955; Cialdini \& Trost, 1998).

Injunctive norms describe the actions most others in a group approve of by telling us what we should or ought to do. They both prescribe accepted actions and proscribe inappropriate behaviors. If these norms are adhered to, individuals receive social acceptance; conversely, if one disregards these norms, the threat of social sanctions looms (Jacobson et al., 2011; Cialdini \& Trost, 1998). When a teacher recommends that a student should study in a particular way, the teacher is promoting an injunctive norm.

In contrast, descriptive norms provide information about the actions most others actually do in a given context, offering a consensus about which behaviors are effective (Kelley, 1967;

Jacobson et al., 2011). Because individuals want to be accurate (Lundgren \& Prislin, 1998), individuals adapt their behaviors to that of the group. In the classroom, a student who bases their studying on the actual study habits of their classmates would be employing a descriptive norm.

Across contexts, individuals often have multiple, sometimes conflicting, social norms that could direct behavior (e.g. Krebs, 1970). Which norm we adhere to is determined partially by the "fit" between the motivations behind a norm and the desired behavior (among other factors such as salience; see Cialdini et al., 1991). Specifically, injunctive norms are most effective when individuals identify strongly with a group, and are thus highly-motivated by social acceptance (Christensen et al.,2004; Jacobson et al., 2011). In contrast, descriptive norms are most effective when situations are ambiguous or novel (Sherif, 1936), as uncertainty 
Running head: STUDYING AND SOCIAL NORMS

heightens the search for correct behaviors (Zebrowitz \& Collins, 1997). When the motivational influence behind a norm matches the goal behind a given behavior, we would expect increased

fit, and thus increased engagement and performance (e.g. Higgins, 2000). In total, injunctive and descriptive norms can differ in their influence, depending on whether a match exists between the motivational pull of the salient norm and the goal of the action (Cialdini \& Trost, 1998).

\section{The Current Study}

It is possible that students study to accommodate the expectations of the course (or to avoid social sanctions), but it is also possible that students study for the purpose of improving their own learning outcomes. If it is the former, an injunctive norm may be a more potent motivator, but if it is the latter, students may be more strongly motivated by a descriptive norm illustrating effective studying behaviors among other group members. Depending on the goal of self-regulated study, whether for meeting the course’s expectations, or for improving one's own ability, we predict that different norms will have different motivational effects.

We examine this hypothesis by directly manipulating the social norm messages students receive during their enrollment in a real, online, Introductory Psychology college course. There are many benefits to embedding experiments in authentic learning environments, particularly in online courses where studying behaviors, such as the number of minutes spent working on practice questions, are logged by default, providing a direct and authentic measure of studying effort (Motz et al., in press). In this particular online course, studying activities can be further split between those that are motivated by meeting the course's expectations (graded work on lesson activities prior to a deadline) and those that are performed purely to improve ability (ungraded attempts on the same activities after the deadline). 
Running head: STUDYING AND SOCIAL NORMS

Students received social norm messages in the form of personalized emails from the instructor at the start of every new content unit. As a social intervention, subtle normative messages have been shown to be an effective “lever of persuasion” (Nolan et al., 2008), and even though email messages may not seem particularly motivating on the surface, research suggests that emails from a teacher do have the power to improve student motivation (Legg \& Wilson, 2009). Moreover, the issue of motivation is even more relevant in online courses, where students are expressly responsible for their own learning activities, and self-determination is the primary predictor of student success (Waschull, 2005).

\section{Method}

\section{Participants}

All students who enrolled in online sections of Introductory Psychology I at Indiana University Bloomington during the Fall 2016 and Spring 2017 semesters constituted a convenience sample. Students were naïve to the specifics of this study, but were informed in the syllabus and introductory lessons that there would be minor variations in course materials for research and assessment purposes. The rights of student participants were protected under a research protocol approved by the Indiana University Institutional Review Board. All students had the same instructor (who is also an author of the current study, Motz). Students who withdrew from the course were excluded from all analyses, while students who enrolled up to 1week late were included. For the 8 students who enrolled in the course in both semesters, only their first (Fall 2016) enrollment is included. In total, 255 students were in the Fall 2016 semester and 496 students were in the Spring 2017 semester, for a combined sample of 751 participants. Aggregate institutional records of these sections indicated that $51 \%$ were female, with an average age of 20.2 years at the time of enrollment. According to self-reported ethnic 
Running head: STUDYING AND SOCIAL NORMS

profiles from these students’ college applications, 58\% were White, 5\% were Black, and 6\% were Hispanic. 25\% were international students.

\section{Procedure}

The online Introductory Psychology course was organized into 7 topical units (the first unit was a short introductory unit and is not included in the current study). Each unit contained several online "lessons," and lessons contained graded online activities that students completed for credit. Students could complete these activities as many times as they wanted, and only their highest recorded score prior to the lesson due date would could toward their grade. After the due date, students could still work through the activities as a studying aid, but they could not improve their recorded grades. A more detailed description of the course, including links to the syllabus and a video walkthrough of an example lesson is available at https://osf.io/2ms4f/wiki/.

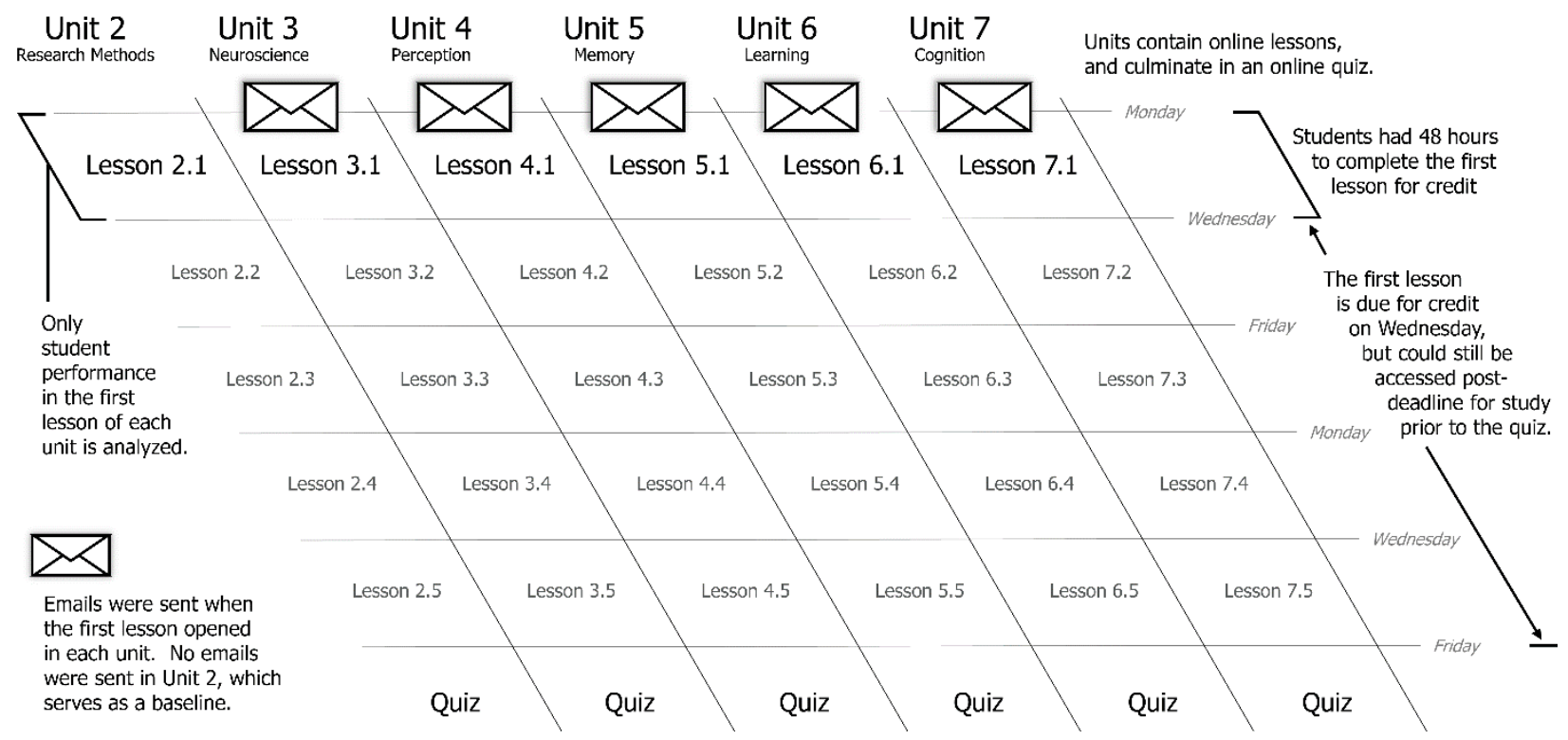

Fig. 1. Visual representation of the course and study design.

Manipulation. At the start of the semester, all enrolled students were randomly assigned to treatment groups: injunctive message, descriptive message, control message, or no 
Running head: STUDYING AND SOCIAL NORMS

message. These groups determined which email (if any) a student would receive on the first day of a new unit in the course, starting in Unit 3, and continuing in every subsequent unit (no emails were sent in Unit 2, providing a baseline measure of student performance). The full text of the emails is available at https://osf.io/98tz5/.

For the injunctive and descriptive message groups, the email pointed out the actual number of times that the student completed lesson activities in the previous unit prior to the quiz opening date (individual data were inserted into the email using the mail merge function in Microsoft Office; Redmond, WA), and this was contrasted with a stated norm, which was always three times the number of activities in the previous unit. Both normative messages, injunctive and descriptive, were intended to increase the number of times that students performed the learning activities, and both messages highlighted the value of practice with the materials for improving scores on the lessons and the quizzes. Students in the injunctive or descriptive message groups who, in the prior unit, had completed the activities at or above the norm were given the control message.

In the injunctive message, the normative content stated that the student should have done the lesson activities about three times per activity. In the descriptive message, the norm stated that the other students in the class did the lesson activities an average of about three times per activity. The latter was not technically inaccurate — even though a minority of students (about 15\%) did the lesson activities three times per activity, the group average was influenced by highly-engaged outliers, and the cumulative means for each unit were close to the norm of three plays per activity. Both the descriptive and injunctive messages ended with a short description of the upcoming unit and a reminder to schedule an appointment to take the quiz. 
Running head: STUDYING AND SOCIAL NORMS

The 'control message’ group’s email did not include any normative content, but it did include the same description of the upcoming unit and reminder about the quiz.

The 'no message' group did not receive any email announcements from the instructor on the first day of each new unit. Of course, if an individual student contacted the instructor directly on the first day of a new unit, an individual reply was not withheld, regardless of condition assignment.

Starting on the second day of each new unit, students all received periodic announcements from the instructor as in the normal conduct of the course (an average frequency of 2 emails per week), with no difference between groups. The only manipulation was the email announcements sent on the first day of each new unit.

Measured Variables. Because this course was fully online, all student activity is timestamped and logged by default. For examining the effects of start-of-unit emails, we focus on five separate measures of self-regulated study behavior and course performance: (1) lesson completion time, the time when students first complete (initially get the highest recorded score before the deadline) all activities in the first lesson in each unit (measured in hours after the lesson unlocks); (2) time-on-task pre-deadline, the cumulative time, in minutes, between initialization timestamps and update timestamps, for every recorded milestone across all activities in the first lesson in each unit, before that lesson was due (which represents assigned student work toward a lesson grade); (3) time-on-task post-deadline, the same cumulative time measure, in minutes, for the activities in the first lesson in the unit, but recorded after the lesson's deadline and before the open date for the unit quiz (which represents ungraded study practice in preparation for the quiz); (4) quiz score, the percent correct (out of 30 items), on the 
Running head: STUDYING AND SOCIAL NORMS

end-of-unit quiz; and (5) cumulative unit score, the weighted average of all course performance within a single unit, according to the weights described in the syllabus for the calculation of final grades. For the first four measures, if a student didn't complete the lesson or the quiz, those data were treated as missing for the current research (even though the student would have received zeros toward the cumulative unit score).

Unit 2, which took place before students received any research intervention, provides a baseline measure of student performance without any email treatment. For each student, for each of the measured variables, we subtracted the observation in Unit 2 from the observation in each subsequent unit (3 through 7), creating a measure of change over baseline. For any student who had missing data for a measured variable in Unit 2 (thus missing a baseline), all subsequent scores for that student, for that variable, were excluded from further analysis.

\section{Bayesian Data Analysis}

We used the framework of a Bayesian ANOVA to analyze all of the difference scores. There are several reasons to prefer Bayesian estimation over traditional frequentist methods (see Kruschke \& Liddell, 2018a, 2018b for extended discussions). Bayesian estimation provides a full posterior distribution for all parameters, and this distribution can be summarized using the 95\% highest density interval (HDI), analogous to but distinct from a 95\% confidence interval. For all parameters we use priors that are vague on the scale of the data (e.g., the priors for experimental effects are wide distributions centered on 0.0), and thus the prior has very minimal effect on the posterior estimate. Full specification of the parameters of the model and their priors, and a more detailed description of the advantages of Bayesian estimation for the present work, is available at https://osf.io/2ms4f/. 
Running head: STUDYING AND SOCIAL NORMS

We utilize Markov chain Monte Carlo (MCMC) methods to estimate the posterior distributions of our parameters with the sampling tool JAGS (Plummer, 2003), along with the statistical programs R and runjags (Denwood, 2013). For all parameter estimates and comparisons presented here, effective sample size is larger than 10,000 to ensure stable estimates of the posterior distributions.

\section{Results}

Across all units and email conditions, students completed the lesson activities an average of 23.0 hours after they opened, roughly halfway between the time when the online lessons unlocked and their deadlines 48 hours later. Students spent an average of 27.1 minutes working on these lesson activities prior to the deadline, and spent another 16.8 minutes on them after the deadline for study prior to taking the quiz. The average quiz score was $79.6 \%$, which constituted $40 \%$ of the cumulative course score. When including zeros for missed assignments and quizzes throughout the semester, the average cumulative score (combining quiz, lesson, and writing assignment scores) was $74.7 \%$, although the actual assigned grades were slightly higher due to course policies allowing students to drop some of their lowest scores in each category.

For each of these measured variables (lesson completion time, time-on-task pre-deadline, time-on-task post-deadline, quiz score, and cumulative score), our models estimated the difference in student performance between Unit 2 (before the email intervention), and each of the subsequent units (which included the email intervention). See Figure 2 for the posterior distributions of these estimates.

Does an Email Improve Student Effort? 
Running head: STUDYING AND SOCIAL NORMS

As a manipulation check, we can start by analyzing whether simply receiving an email (of any form) improves studying behavior and student performance. To draw this contrast, we average the parameter estimates at every step in the MCMC chains for all students who received an email at the start of each new unit (averaging the effects of injunctive, descriptive, and control messages), and then subtract the parameter estimates for the 'no message' condition (students who did not receive any such emails on the first day of a new unit). If the $95 \%$ highest density interval (HDI) of these estimated difference values excludes zero, then the data support a credibly non-zero effect of instructor emails for that measure.

Students who received instructor emails at the start of each unit had a greater improvement in lesson completion time pre-to-post intervention, compared with students who did not receive any start-of-unit emails. Specifically, the emails caused students to finish the first lesson in the unit 1.57 hours earlier (95\% HDI: -2.87 to -0.17 ) than students in the 'no message’ group. This reliable acceleration in completion time was not caused by students rushing through the assignments; if anything, the emails seemed to cause students to spend more time on the lesson activities prior to the deadline (difference mode $=1.16$ minutes longer on activities in email groups), although this increase in time-on-task was modest in proportion to uncertainty, and the 95\% HDI overlapped zero (-0.39 to 2.99). There was no reliable average effect of emails on studying time after the deadline (difference mode $=-1.16$ minutes; 95\% HDI: -4.05 to 1.9 ) nor quiz scores (difference mode $=0.75 \%$; $95 \%$ HDI: -0.45 to 1.91 ). But combining all lesson, assignment, and quiz scores, instructor emails at the start of each unit 
Running head: STUDYING AND SOCIAL NORMS

reliably caused students to get higher cumulative scores in those units than students in the 'no message’ group (difference mode $=3.48 \%$; 95\% HDI: 1.00 to 5.72$)^{1}$.

\section{Does a Normative Message Improve Student Effort?}

Two of the emails included a normative message intended to persuade students to increase their studying effort (either injunctive or descriptive), while a third email was a control message, simply intended to inform students about the new unit (no normative content). Having established that emails had a measurable effect on student behavior, we can now ask whether the content of the email affected student effort. For this analysis, we average the estimated effects of injunctive and descriptive messages, and contrast this with the estimated effect of the control message at each step in the MCMC chains.

Compared with the control message, there was no reliable effect of the normative messages on lesson completion time (difference mode $=-0.35$ hours; 95\% HDI: -1.62 to 1.16), but the normative messages did cause students to spend more time on the lesson activities both before the deadline (difference mode $=3.5$ minutes; 95\% HDI: 1.61 to 5.45), and after the deadline for study (difference mode $=5.94$; 95\% HDI: 1.3 to 10.4). Summing the time-on-task estimates before and after the lesson deadline, the normative messages caused students to spend a total of 9.23 more minutes (95\% HDI: 4.45 to 14.3) working on lesson activities than students who received the control message. The normative messages also seemed to cause a positive shift in quiz scores (difference mode $=1.24 \%$ ), however, the 95\% HDI slightly overlapped zero (0.05\% to $2.59 \%$ ), preventing us from drawing strong inferences about the average effects of

\footnotetext{
${ }^{1}$ Actual assigned course grades (including unit 1 and unit 2 performance, and also dropping lowest scores in each grading category) were practically identical between conditions, and there is no evidence that students' end-ofsemester grades were affected by the study manipulations.
} 
Running head: STUDYING AND SOCIAL NORMS

normative messages on quiz performance. There was no effect of normative messages on cumulative scores (difference mode $=0.39 \%$; 95\% HDI: $-1.96 \%$ to $2.72 \%$ ).

The behaviors of students who received the control message, which had no direct or implied instructions for students to improve their studying (it simply informed students about the new unit), can also be contrasted with the students in the 'no message' group. In this exploratory analysis, parameter estimates suggest that the control message may have attenuated student effort compared with the 'no message' group. Prior to the deadline, students who received the control message spent roughly the same amount of time on the lesson activities as students in the 'no message’ group (difference mode $=-1.08$ minutes; 95\% HDI: -3.28 to 1.13 ), but after the deadline, however, when students would practice the lesson activities for study, the control message caused students to spend reliably less time on the activities than the 'no message' group (difference mode $=-5.06$ minutes; 95\% HDI -9.94 to -0.17). Combining activity before and after the deadline, the control message caused a 6.15 minute reduction in time on task (95\% HDI: 11.4 to -0.742 ) compared with the behavior of students who received no email, suggesting that a purely informative message can cause decrements in student effort. 
Running head: STUDYING AND SOCIAL NORMS
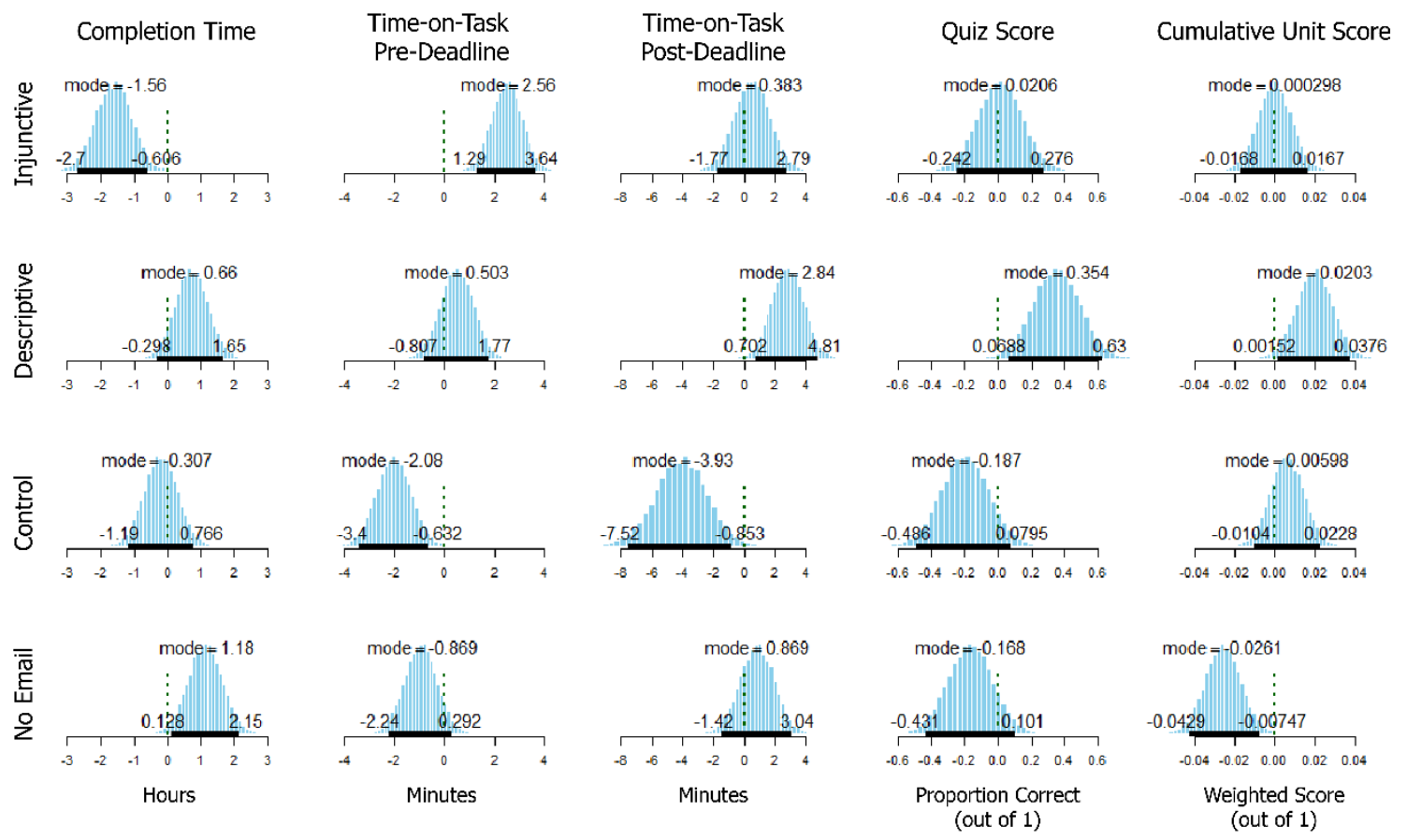

Fig. 2. Posterior distributions (with 95\% HDI spans shown in black) for credible experimental effects on activity completion time $\left(1^{\text {st }}\right.$ column$)$, time spent on activities before the deadline $\left(2^{\text {nd }}\right.$ column), time spent on activities after the deadline ( $3^{\text {rd }}$ column), end of unit quizzes $\left(4^{\text {th }}\right.$ column), and cumulative unit scores ( $5^{\text {th }}$ column). Each row represents a different condition: injunctive message (top row), descriptive message ( $2^{\text {nd }}$ row), control message ( $3^{\text {rd }}$ row), and no message (bottom row). Dotted green lines (over 0) indicate the average for the total study sample.

Did Injunctive and Descriptive Messages have Different Effects on Student Effort?

To evaluate the differences between the two normative messages, we can calculate the difference between estimated effects of the injunctive message and the descriptive message at every step in the MCMC chains, for each of the measured variables.

Students who received the injunctive message (recommending that they should have done the lessons more) completed the lesson activities 2.25 hours earlier (95\% HDI: -4.02 to -0.71 ) 
Running head: STUDYING AND SOCIAL NORMS

than students who received the descriptive message (recommending that the other students in the class had done the lessons more). The injunctive message also caused students to spend reliably more time working on lesson activities before the deadline (difference mode $=1.88$ minutes; 95\% HDI: 0.02 to 3.98) than the descriptive message. After the deadline, however, there was evidence for a reversal, as the descriptive message seemed to cause students to spend more time practicing the activities after they were due (difference mode $=2.53$ minutes; 95\% HDI: -0.85 to 5.67) than the injunctive message, but uncertainty in these data caused this posterior distribution to overlap zero. There were also trends for the descriptive message to cause greater improvements in quiz scores (difference mode $=1.11 \%$; 95\% HDI: -0.36 to 2.56 ) and cumulative scores (difference mode $=2.16$; $95 \%$ HDI: -0.90 to 4.82 ), but these posterior distributions also slightly overlapped zero. Nevertheless, for time-on-task, the interaction between normative messages (descriptive / injunctive) and deadline (before / after) was significant (difference of differences mode $=4.64$ minutes; 95\% HDI: 0.46 to 8.09 ). It is clear that the effect of a normative message on time-on-task is contingent on whether the activity is before the deadline (to get a grade), or after the deadline (to study for a quiz).

To gain a clearer picture of the effects of the injunctive and descriptive messages, we can also draw exploratory contrasts with the total study sample (directly analyzing the estimated deflections for each condition), in order to determine the net benefit of each treatment. Compared with all other conditions, the injunctive message caused students to complete the first lesson 1.56 hours earlier (95\% HDI: -2.7 to -0.61) than the class average, while the descriptive message trended toward a later-than-average completion time, although this trend was not significant (mode $=0.66$ hours; $95 \%$ HDI: -0.3 to 1.65 ). Similarly, the injunctive message caused students to spend 2.56 more minutes (95\% HDI: 1.29 to 3.64) on the lesson 
Running head: STUDYING AND SOCIAL NORMS

activities prior to the deadline, but there was no reliable effect of the descriptive message on time-on-task pre-deadline (mode $=0.5$ minutes; 95\% HDI: -0.81 to 1.77 ). After the deadline a reversal was again apparent: there was no reliable effect of injunctive messages on time-on-task post-deadline (mode $=0.38$ minutes; $95 \%$ HDI: -1.77 to 2.79 ), but the descriptive message caused students to spend 2.84 more minutes (95\% HDI: 0.7 to 4.81 ) practicing the lessons after they were due, as compared with the class average. The descriptive message also caused students to get higher scores on their end-of-unit quizzes than the study sample (mode $=1.18 \%$; 95\% HDI: 0.23 to 2.1), but there was no reliable effect of the injunctive message on quiz scores (mode $=0.07 \%$; 95\% HDI: -0.81 to 0.92 ). Cumulative scores were similarly not affected by the injunctive message (mode $=0.03 \%$; $95 \%$ HDI: -1.68 to 1.67 ), and again a positive effect of the descriptive message on cumulative scores was observed (mode $=2.03 \%$; 95\% HDI: 0.15 to 3.76).

In total, we find that the injunctive message caused reliable improvements in completion time and time-on-task prior to the lesson assignments' deadlines, while the descriptive message caused reliable improvements in time-on-task after the deadline. Commensurate with the view that additional effort after the deadline represents practice in preparation for the quiz, we also find that the descriptive message (and not the injunctive message) caused reliably higher quiz performance than other conditions.

\section{Discussion}

This study examined whether injunctive or descriptive norms would better-motivate selfregulated studying behaviors in an authentic college course. Teachers frequently use injunctive norms to encourage studying, but our results show that injunctive messages primarily affected effort on activities explicitly required for the course. On the other hand, descriptive norms had 
Running head: STUDYING AND SOCIAL NORMS

greater benefit for optional, ungraded activities (i.e. work after the due date), and moreover, had greater benefit for learning outcomes. In other words, when the goal of studying was to comply with course requirements, injunctive norms better-motivated behavior change, but when the goal of studying was to improve knowledge, descriptive norms had a stronger influence. Considering that the overall goal of education is to promote learning (and not to promote conformity to instructor expectations), our results clearly suggest that descriptive norms have greater value for motivating self-regulated study.

Beyond their differences in normative content, these two messages also differ in their support for student autonomy, as the statement of what a student should do clearly implies more controlling instructional behavior (Reeve \& Jang, 2006). Self-determination theory (Deci \& Ryan, 1987) broadly favors the use of autonomy-supportive teaching for improving student motivation, but experimental evidence in support of this claim has been elusive (e.g., Furtak \& Kunter, 2012). Readers may interpret our current results to suggest that the more autonomysupportive message (descriptive norm) had a greater effect on student motivation, but some caution is warranted. Remember that the more controlling message (injunctive norm) was not motivationally impotent, as it did reliably improve both completion time and time-on-task on graded homework assignments. In contrast, the descriptive message prompted increased independent ungraded study and benefited quiz performance. Again, the normative messages rendered student effort differentially depending on the goal of the actions, whether completing lessons for credit or to improve knowledge. This conclusion also fits with past educational research demonstrating that students’ particular goals will moderate the effects of different motivational strategies (Boekaerts \& Corno, 2005). For example, correlational research finds that when students are less self-motivated, they are more sensitive to teachers who behave in 
Running head: STUDYING AND SOCIAL NORMS

controlling ways (Soenens et al., 2012), students who are interested in a topic receive more benefit from instruction that supports autonomy than students who have less interest (Wijnia et al., 2014), and extrinsically-motivated students are more likely to exhibit increased participation during gamified learning activities (Buckley \& Doyle, 2014). The current study provides more direct experimental evidence that efforts to improve student behavior may have different mileages, depending on whether the motivational strategy complements the student's goals for engaging in learning activities.

These findings also have important implications for our understanding of normative influence and the efficacy of social norm interventions. Although suggested in past research (Jacobsen et al. 2011; Cialdini \& Trost, 1998), the assertion that "fit” matters in normative interventions has not been directly tested. Our study provides initial evidence that norms have a stronger influence on behavior when the motivational pull of the norm matches the goal of the behavior. Thus, interventionists should carefully examine the underlying goals of their populations of interest to design norm interventions that compliment these goals.

The results of this study also have broad practical implications for online communications with students. First, and consistent with past work (Legg \& Wilson, 2009), we found that emails from an instructor motivated students to complete activities earlier. Importantly, this did not come at a cost to students' effort on the activities, and students who got emails also performed better on quizzes. Second, our results suggest that any messages sent to students should contain a clear call to action, instead of being strictly informative. On some measured variables, the purely informative (control) message caused lower effort than no email at all. The positive effect of behavioral guides delivered via email might have been particularly evident in the current online class, where in-person contact is not possible. But more broadly, providing students with 
Running head: STUDYING AND SOCIAL NORMS

normative feedback will give insight into the behaviors necessary to do well and current results suggest it will improve effort.

In our work, we intentionally focused on providing injunctive and descriptive norms about behaviors (e.g., the number of times a student has attempted a question set) instead of performance (e.g., grades on assignments and quizzes). Although it is common to provide students information about how their grades compare to others in the class or to past classes (Schwendimann et al., 2017), this social comparison information would likely be threatening to the most vulnerable students (i.e. those struggling in the course), especially if the outcomes are seen as unobtainable (e.g. Lockwood \& Kunda, 1997). Instead, we advocate for instructors to motivate behavior change by providing social comparison based strictly on improvable behavioral measures, carefully avoiding comparisons that students might interpret as assessments of their intelligence or innate ability, for instance (Dweck, 2006).

\section{Conclusion}

Instructors often invoke injunctive norms by telling students they should study more, and while these messages may improve compliance with the course requirements, we find no evidence suggesting that they improve learning outcomes. Alternatively, a descriptive norm, comparing a student's self-regulated studying behaviors with the behaviors of their peers, may provide the right motivational pull to cause a student to improve their learning performance. Normative emails to students best increase motivation and effort when the motivational pull of the norm matches the goal of the learning activity. 
Running head: STUDYING AND SOCIAL NORMS

\section{References}

Ariel, R., \& Karpicke, J. D. (2018). Improving self-regulated learning with a retrieval practice intervention. Journal of Experimental Psychology: Applied, 24, 43 - 56.

Asch, S. E. (1956). Studies of independence and conformity: A minority of one against a unanimous majority. Psychological monographs: General and applied, 70, 1 - 70.

Bjork, R. A., Dunlosky, J., \& Kornell, N. (2013). Self-regulated learning: Beliefs, techniques, and illusions. Annual Review of Psychology, 64, 417 - 444.

Boekaerts, M. \& Corno, L. (2005). Self-regulation in the classroom: A perspective on assessment and intervention. Applied Psychology: An International Review, 54, 199 - 231.

Buckley, P., \& Doyle, E. (2014). Gamification and student motivation. Interactive Learning Environments, 24, $1162-1175$.

Carvalho, P. F., Braithwaite, D. W., de Leeuw, J. R., Motz, B. A., \& Goldstone, R. L. (2016). An in-vivo study of self-regulated study sequencing in introductory psychology courses. PLoS ONE, 11, e0152115.

Christensen, P. N., Rothgerber, H., Wood, W., \& Matz, D. C. (2004). Social norms and identity relevance: A motivational approach to normative behavior. Personality and Social Psychology Bulletin, 30, 1295 - 1309.

Cialdini, R. B., Kallgren, C. A., \& Reno, R. R. (1991). A focus theory of normative conduct: A theoretical refinement and reevaluation of the role of norms in human behavior. Advances in Experimental Social Psychology, 24, $201-234$ 
Running head: STUDYING AND SOCIAL NORMS

Cialdini, R. B., \& Trost, M. R. (1998). Social influence: Social norms, conformity and compliance. In D. T. Gilbert, S. T. Fiske, \& G. Lindzey (Eds.), The handbook of social psychology (pp. 151-192). New York, NY, US: McGraw-Hill.

Ciccone, D. S., \& Brelsford, J. W. (1976). Spacing repetitions in paired-associate learning: Experimenter versus subject control. Journal of Experimental Psychology: Human Learning and Memory, 2, 446 - 455.

Deci, E. L. \& Ryan, R. M. (1987). The support of autonomy and the control of behavior. Journal of Personality and Social Psychology, 53, 1024 - 1037.

Denwood, M. J. (2013). runjags: An R package providing interface utilities, distributed computing methods and additional distributions for MCMC models in JAGS. Journal of Statistical Software.

Deutsch, M., \& Gerard, H. B. (1955). A study of normative and informational social influences upon individual judgment. The Journal of Abnormal and Social Psychology, 51, 629 - 636.

Dunlosky, J., Rawson, K. A., Marsh, E. J., Nathan, M. J., \& Willingham, D. T. (2013). Improving students’ learning with effective learning techniques: Promising directions from cognitive and educational psychology. Psychological Science in the Public Interest, 14, 4 58.

Dweck, C. (2006). Mindset: The new psychology of success. New York: Random House.

Fernandez, J., \& Jamet, E. (2017). Extending the testing effect to self-regulated learning. Metacognition and Learning, 12, 131 - 156.

Furtak, E. M. \& Kunter, M. (2012). Effects of autonomy-supportive teaching on student learning and motivation. Learning, Instruction, and Cognition, 80, 284 - 316. 
Running head: STUDYING AND SOCIAL NORMS

Higgins, E. T. (2000). Making a good decision: Value from fit. American Psychologist, 55, 1217 $-1230$.

Jacobson, R. P., Mortensen, C. R., \& Cialdini, R. B. (2011). Bodies obliged and unbound: Differentiated response tendencies for injunctive and descriptive social norms. Journal of Personality and Social Psychology, 100, 433 - 448.

Kelley, H. H. (1967). Attribution theory in social psychology. In D. Levine (ed.), Nebraska Symposium on Motivation (Volume 15, pp. 192-238). Lincoln: University of Nebraska Press.

Kruschke, J. K. \& Liddell, T. M. (2018a). The Bayesian New Statistics: Hypothesis testing, estimation, meta-analysis, and power analysis from a Bayesian perspective. Psychonomic Bulletin \& Review, 25, 178 - 206.

Kruschke, J. K. \& Liddell, T. M. (2018b). Bayesian data analysis for newcomers. Psychonomic Bulletin \& Review, 25, 155 - 177.

Krebs, D. L. (1970). Altruism: An examination of the concept and a review of the literature. Psychological Bulletin, 73, 258 - 302.

Legg, A. M., \& Wilson, J. H. (2009). E-mail from professor enhances student motivation and attitudes. Teaching of Psychology, 36, 205 - 211.

Lockwood, P., \& Kunda, Z. (1997). Superstars and me: Predicting the impact of role models on the self. Journal of Personality and Social Psychology, 73, 91 - 103.

Lundgren, S. R., \& Prislin, R. (1998). Motivated cognitive processing and attitude change. Personality and Social Psychology Bulletin, 24, 715 - 726. 
Running head: STUDYING AND SOCIAL NORMS

McCabe, D. B. \& Meuter, M. L. (2011). A student view of technology in the classroom: Does it enhance the seven principles of good practice in undergraduate education?. Journal of Marketing Education, 33, 149 - 159.

Motz, B. A., Carvalho, P. F., de Leeuw, J. R., Goldstone, R. L. (in press). Embedding experiments: Staking causal inference in authentic educational contexts. Journal of Learning Analytics.

Nolan, J. M., Schultz, P. W., Cialdini, R. B., Goldstein, N. J., \& Griskevicius, V. (2008). Normative social influence is underdetected. Personality and Social Psychology Bulletin, 34, $913-923$.

Parkes, J., \& Harris, M. B. (2002). The purposes of a syllabus. College Teaching, 50, 55-61.

Plummer, M. (2003). JAGS: A program for analysis of Bayesian graphical models using Gibbs sampling. In Proceedings of the 3rd International Workshop on Distributed Statistical Computing.

Reeve, J. \& Jang, H. (2006). What teachers say and do to support students' autonomy during a learning activity. Journal of Educational Psychology, 98, 209 - 218.

Schwendimann, B. A., Rodríguez-Triana, M. J., Vozniuk, A., Prieto, L. P., Boroujeni, M. S., Holzer, A., Gillet, D., \& Dillenbourg, P. (2017). Perceiving learning at a glance: A systematic literature review of learning dashboard research. IEEE Transactions on Learning Technologies, 10, $30-41$.

Sherif, M. (1936). The psychology of social norms. New York: Harper. 
Running head: STUDYING AND SOCIAL NORMS

Soenens, B., Sierens, E., Vansteenkiste, M.,Dochy, F., \& Goossens, L. (2012). Psychologically controlling teaching: Examining outcomes, antecedents, and mediators. Journal of Educational Psychology, 104, 108 - 120.

Waschull, S. (2001). The online delivery of psychology courses: Attrition, performance, and evaluation. Teaching of Psychology, 28, 143 - 147.

Wijnia, L., Loyens, S. M. M., Derous, E., \& Schmidt, H. G. (2014). Do students’ topic interest and tutors' instructional style matter in problem-based learning? Journal of Educational Psychology, 106, 919 - 933.

Zebrowitz, L. A., \& Collins, M. A. (1997). Accurate social perception at zero acquaintance: The affordances of a Gibsonian approach, Personality and Social Psychology Review, 1, 203 222. 